\title{
CURSO DE ESTUDIOS COMPARATIVOS SOBRE "ADMINISTRACION MUNICIPAL Y DESARROLLO NACIONAL»
}

$352: 338.984 .3(46)$

por

\section{José Fariña Jamardo}

SUMARIO: I. LA IULA: OBJETIVOS Y ACTIVIDADES.-II. EL CURSO DE «ADMINISTRACION MUNICIPAL Y DESARROLLO NACIONAL».-III. LA FASE ESPAÑOLA.

Durante los días 4 al 20 de septiembre de 1974 ha tenido lugar, en la Escuela Nacional de Administración Local del Instituto de Estudios de Administración Local, el I Curso de Administración Municipal y Desarrollo Nacional, organizado por dicho Instituto en colaboración con la Unión Internacional de Gobiernos Locales (IULA), y que constituye la primera fase del Curso de Estudios Comparativos, núm. 23, de la IULA.

Por ser éste el primer Curso que la Unión Internacional de Gobiernos Locales realiza en castellano y, también, la primera vez que un Curso de este carácter se celebra en nuestro país, corriendo su organización en España, a petición de IULA, a cargo del Instituto de Estudios de Administración Local, lo que pone de relieve el prestigio internacional del mismo, vamos a referirnos a su contenido y desarrollo, previa una breve información sobre dicha Unión Internacional. 


\section{LA IULA: OBJETIVOS Y ACTIVIDADES}

La Unión Internacional de Gobiernos Locales (IULA) fue fundada en 1913 y en la actualidad es una organización a escala mundial, de la que son miembros más de sesenta países.

Su importancia se deduce del hecho de que a IULA le ha sido concedido status consultivo por el Consejo Económico y Social de las Naciones Unidas y por la UNESCO, UNICEF, WHO y Consejo de Europa.

Los cuatro objetivos fundamentales a cubrir por la Unión Internacional de Gobiernos Locales, todos ellos dentro del marco de la Vida local, son:

- Fomentar la causa de la autonomía municipal.

- Promover el nivel de calidad de la Administración municipal.

- Estudiar todas las cuestiones relativas a la Administración municipal y al bienestar de los ciudadanos.

- Estimular la participación de la población en los asuntos cívicos.

En su carácter de organización internacional, y como especial objetivo, IULA pretende también establecer la amistad y el buen entendimiento entre todos los pueblos del mundo.

Entre las actividades de IULA, y como muy importante, figura su programa de formación y adiestramiento, encaminado a mejorar la calidad y capacidad de la Administración municipal, especialmente en los países menos desarrollados, habiendo realizado desde 1964 un total de 22 Cursos de Administración Municipal Comparada, la mayoría en inglés y algunos en francés.

\section{EL CURSO DE «ADMINISTRACION MUNICIPAL Y DESARROLLO NACIONAL»}

Como ya señalamos anteriormente, es el primer Curso de la IULA en lengua castellana y ha contado con la cooperación de los Gobiernos de España, Países Bajos y Alemania Federal, y la asistencia especial del Public Administration Promotion Centre en Berlín y del International Centre for Municipal Credit en La Haya, 
además de la del Instituto de Estudios de Administración Local, a quien ha correspondido la organización y ejecución en España de la primera parte del Curso.

Las características principales son:

a) Objetivo. Estudiar comparativamente el papel que desempeñan las autoridades municipales en el desarrollo nacional, con especial atención a los problema de gestión administrativa y financiera, aspectos presupuestarios del desarrollo, planificación física y técnica para la toma de decisiones. También se incluye un estudio especial sobre la contribución de las instituciones municipales de crédito al desarrollo local.

b) Participantes. El Curso fue concebido para:

- Funcionarios públicos de los Ministerios y Oficinas centrales que se ocupen directamente de la dirección y fomento de la Administración municipal.

- Funcionarios y miembros de gobiernos provinciales, municipales o federativos.

- Personal docente de Universidades e Institutos dedicados a la formación y adiestramiento de funcionarios o empleados municipales.

Los asistentes al Curso, todos ellos pertenecientes a alguno de los tres grupos anteriores, son veinte, y proceden de nueve países, conforme al siguiente detalle: Argentina, dos; Colombia, dos; Costa Rica, dos; Ecuador, dos; España, dos; Honduras, uno; México, cinco; Perú, uno, y Venezuela, tres.

c) Programa. El Curso, conforme con su denominación general de "Estudios Comparativos de Administración Municipal», se desarrolla en tres países y en las siguientes fechas:

España: 4 al 20 de septiembre. En el IEAL (Madrid).

Holanda: 22 al 29 de septiembre. En La Haya.

30 de septiembre al 5 de octubre. Visita a las Municipalidades de la Provincia de Friesland.

Alemania: 6 al 19 de octubre. En Bremen y Berlín.

Holanda: 20 al 29 de octubre. Seminario final en La Haya. 30 de octubre. Clausura.

d) Desarrollo. El Curso comprende: conferencias, seminarios, coloquios y visitas a instituciones locales de los países referidos. 
Los participantes deberán recopilar y analizar la experiencia adquirida durante el Curso y prepararán un informe relacionando sus observaciones en los tres países europeos visitados a países menos desarrollados de otras partes del mundo. La conclusiones de estos informes serán publicadas y distribuidas una vez clausurado el Curso.

\section{LA FASE ESPAÑOLA}

Se desarrolló por el Instituto de Estudios de Administración Local a través de su Escuela Nacional de Administración Local, a cuyo cargo estuvo la organización y ejecución de esta fase del Curso, con sujeción al siguiente detalle:

a) Inauguración. Tuvo lugar, en el Salón de Actos del Instituto, el día 4 de septiembre, a las 19 horas, bajo la presidencia del Director del Instituto, D. José Antonio García-Trevijano y Fos, interviniendo D. Julián Carrasco Belinchón, Director de la Escuela Nacional de Administración Local, y Mr. H. J. P. Allen, Director de los Cursos de Formación y Adiestramiento de la IULA.

b) Duración. Del 4 al 20 de septiembre de 1974 .

c) Desarrollo. Comprendió conferencias y coloquios y visitas a Centros y Corporaciones locales, en Madrid y Provincias limítrofes.

d) Conferencias y conferenciantes. Las conferencias, todas ellas seguidas de animados e incisivos coloquios, fueron desarrolladas por los Profesores que se expresan, de acuerdo con el siguiente programa:

Día 5. «Descentralización administrativa»: Sr. Garrido Falla. «Haciendas locales»: Sr. Albiñana García-Quintana.

Día 6. «Descentralización administrativa»: Sr. Garrido Falla. «Haciendas locales»: Sr. Albiñana García-Quintana.

Día 9. «Estructuras locales»: Sr. Morell Ocaña. «Organización administrativa española»: Sr. García-Trevijano y Fos.

Día 10. «Estructuras locales»: Sr. Morell Ocaña. «Elección de los órganos políticos locales»: Sr. García-Trevijano y Fos. «Procedimiento administrativo español»: Sr. Guaita Martorell.

Día 11. "Actuación de las Corporaciones locales españolas»: Señor García-Trevijano y Fos. "Garantías jurisdiccionales en el Derecho español»: Sr. González Pérez. 
Día 12. «Servicios locales españoles»: Sr. D’Anjou González. «Financiación local»: Sr. Martín Sampedro. «Función pública local»: Sr. Carrasco Belinchón.

Día 13. «Función pública española»: Sr. De la Vallina Velarde. «Financiación local»: Sr. Martín Sampedro.

Día 18. "Hacienda pública española»: Sr. Fuentes Quintana. «Derecho urbanístico español»: Sr. Galvañ Escutía.

Día 20. «Derecho urbanístico español»: Sr. Galvañ Escutía. «Régimen jurídico administrativo español»: Sr. Boquera Oliver.

La tarde de los días 5 y 6 fue dedicada a presentación de los participantes, bajo la dirección de Mr. Allen, y la de los días 18 y 20, a discusión de los aspectos examinados en las visitas realizadas.

e) Visitas. Fueron las siguientes:

Día 9. Al Ayuntamiento de Madrid. Coloquio en el Salón de Tapices, bajo la presidencia del Alcalde accidental, previa exposición de la organización administrativa municipal por el Secretario general, Vicesecretario, Interventor y Depositario, y de la estructura y problemas de los Servicios por los Delegados de los mismos, con numerosas intervenciones de los cursillistas.

Día 11. A los Servicios asistenciales y culturales de la Diputación Provincial de Madrid, Ciudad Social de Ancianos «Francisco Franco" y Ciudad Escolar Provincial "Francisco Franco», cuyas instalaciones, servicios y dependencias recorrieron con detenimiento, siéndoles explicado el funcionamiento de dichos Centros por los respectivos Directores, quienes contestaron a las muchas preguntas que se les fueron formuladas.

Día 13. Al Banco de Crédito Local de España. Exposición por los funcionarios directivos del Banco, de su organización y sistema de financiación a las Corporaciones locales, seguida de coloquio, en el que participaron todos los componentes del Curso.

Día 16. Al Ayuntamiento de Toledo, aspectos monumentales de la ciudad y Servicios, especialmente a la estación depuradora de agua potable, con explicaciones de los funcionarios directivos y técnicos del Ayuntamiento, seguidas de un coloquio presidido por el Alcalde de la ciudad.

Día 17. Al Ayuntamiento y Diputación Provincial de Avila, cuyas características fueron expuestas por sus respectivos Presidentes, al igual que las del Asocio de la Tierra de Avila, completándose con el examen de la zona monumental de la ciudad.

Día 19. Al Ayuntamiento de Guadalajara, en cuyo Salón de 
Sesiones, y bajo la presidencia del Alcalde, el Secretario general hizo una exposición detallada sobre los aspectos económicourbanísticos de la ciudad, interviniendo también los Jefes de las distintas dependencias municipales y los cursillistas en un animado coloquio sobre la problemática urbanística de Guadalajara, completado con el examen sobre el terreno de los Polígonos del Balconcillo y del Henares, como zonas industrial-residencial e industrial, respectivamente.

f) Clausura. Se realizó, en el Salón de Actos del Instituto, en la tarde del día 20 de septiembre, bajo la presidencia del Excmo. Señor D. José Antonio García-Trevijano y Fos, interviniendo en representación de los participantes el Sr. Guiza Alday, Oficial Mayor del Estado de Guanajuato, y el Director de los Cursos de Formación y Adiestramiento de la IULA, Mr. Allen, quienes pusieron de relieve el éxito de la fase española del Curso e hicieron patente su agradecimiento a los Profesores y al Instituto, y en especial al Director de la Escuela, por la magnífica organización y desarrollo de las actividades, cerrando el acto el Sr. García-Trevijano, que agradeció a los señores Guiza Alday y Allen sus palabras y abogó porque esta iniciada colaboración Instituto de Estudios de Administración Local y Unión Internacional de Gobiernos Locales (IULA) se intensifique en el futuro. 


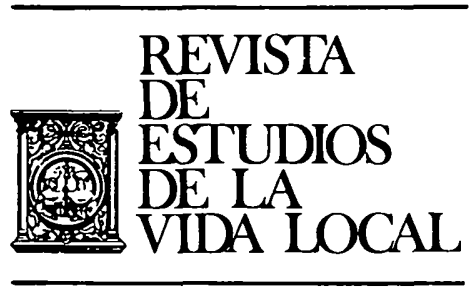

III. ESTADISTICA

REVL-1974, núm. 183. FARIÑA JAMARDO, JOSE. CURSO DE ESTUDIOS COMPARATIVOS SOBRE ... 
